\title{
The Past, the Present, the Future, and Occupational Self-efficacy: An Attributions and Cultural Differences Perspective between Postgraduate Students in the United States and Mexico
}

El pasado, el presente, el futuro y la autoeficacia ocupacional: una perspectiva de atribuciones y diferencias culturales entre estudiantes de posgrado en Estados Unidos y México

Daniel Arturo Cernas Ortiz ${ }^{1}$

Fecha de recepción: 12 de febrero de 2021

Fecha de aceptación: 27 de mayo de 2021 


\section{Abstract}

This study's objective was to examine empirical relationships between three dimensions of time perspective (future, present fatalistic, and past negative) and occupational self-efficacy. Occupational self-efficacy refers to the belief that one can mobilize necessary resources to meet the situation demands encountered in a work-related occupational domain (Schyns \& von Collani, 2002). By surveying Mexican $(n=286)$ and U.S. $(n=272)$ respondents, we also tested the moderating role of culture. Regression analyses revealed that time perspective dimensions have significant associations with occupational self-efficacy, being future time perspective more potent than its past negative and present fatalistic counterparts. Moderation analyses indicated that none of the examined time perspective-self-efficacy relationships varied significantly between the U.S. and Mexico. Overall, this study suggests that relationships between time perspective and occupational self-efficacy vary according to different temporal dimensions, that future time perspective is key to developing occupational self-efficacy, and that cultural values may not significantly influence on the time perspective-occupational self-efficacy connection.

Keywords: time perspective, self-efficacy, cultural differences, moderation analysis.

\section{Resumen}

El objetivo de este trabajo fue examinar la relación entre tres dimensiones de perspectiva de tiempo (futura, presente fatalista y pasado negativa) y la autoeficacia ocupacional. La autoeficacia ocupacional se refiere a la creencia personal de poder movilizar los recursos necesarios para afrontar las demandas inherentes al trabajo en un dominio ocupacional determinado (Schyns \& von Collani, 2002). Mediante una encuesta aplicada a respondientes mexicanos $(n=286)$ y estadounidenses $(n$ =272), también se puso a prueba el papel de la cultura. Un análisis de regresión reveló que las dimensiones de la perspectiva de tiempo analizadas tienen relaciones significativas con la autoeficacia ocupacional, siendo la perspectiva futura de tiempo más potente que sus contrapartes pasado negativa y presente fatalista. Ninguna de las relaciones examinadas entre la perspectiva de tiempo y la autoeficacia varió significativamente entre EE. UU. y México. En general, las relaciones entre la perspectiva de tiempo y la autoeficacia ocupacional varían de acuerdo con diferentes dimensiones temporales. Los valores culturales podrían no ejercer influencia en la conexión entre la perspectiva de tiempo y la autoeficacia.

Palabras clave: perspectiva de tiempo, autoeficacia, diferencias culturales, análisis de moderación. 


\section{Introduction}

B eginning with Bandura's (1977) seminal work on social cognitive theory, research overwhelmingly supports self-efficacy as an essential factor in human motivation and action. As a central element of the theory, self-awareness implies that people consciously attempt to explore and make sense of cognitions and beliefs about the self. Indeed, it seems obvious that any decision to take, delay, or avoid an action is informed by the belief one can execute that course of action. An equally important, yet largely unconscious factor can also influence that decision - the psychological sense of time. Mental temporality is key to understand human conduct because it only comes to exist in and through time (Navarro et al., 2015). In organizations, for instance, a temporal focus on the past could make individuals to compare their present work conditions with past ones, thus influencing their present job satisfaction and turnover intentions (Ship et al., 2009). Unlike a mere temporal focus, time perspective (TP), or the unconscious process of partitioning the flow of experiences into past, present, and future categories (Zimbardo \& Boyd, 1999), is a more comprehensive concept encompassing experiential and emotional consequences beyond the purely cognitive domain. In turn, TP influences affective states, decisions, and actions (Stolarski et al., 2014; Sobol-Kwapinska et al., 2018) and, thus, it is important to better understand human behavior at work.

As fundamental psychological constructs, efficacy beliefs and TP are related. Research, however, has focused almost exclusively on future TP, reporting medium to relatively large correlations between this TP and self-efficacy. Cernas-Ortiz and Mercado-Salgado (2020), and Park and Jung (2015), for example, reported effect sizes ( $\mathrm{r}$ ) of .31 and .45, respectively. Cernas-Ortiz and Mercado-Salgado (2020) argue that such variables are related because visualizing the future, setting goals, and working hard toward their attainment should contribute to self-efficacy's main source: successful performance experiences, more widely known as enactive mastery (Bandura, 1977, 1995).

Still, the link between TP and self-efficacy needs further scrutiny. In the first place, existing explanations need more nuanced elaborations because they assume that performance information produced by TP influences on actual enactive mastery transforms automatically into efficacy beliefs. This explanation is incomplete, as from an attributional perspective, judgments of personal efficacy reflect an inferential process whereby the relative contributions of personal and situational factors are weighted and integrated (Gist \& Mitchell, 1992). Therefore, although two individuals may have the same objective skill level, they may still perceive different self-efficacy degrees depending upon their attributions following performance outcomes. Indeed, examining attributions is important as they help to explain many interrelated constructs including cognitions, emotions, and actions (Weiner, 2019).

A second reason why the TP-efficacy beliefs relationship needs further examination is that the nature of it may vary as a function of the individual's favored TP. Although one can envision a straightforward connection between future TP and self-efficacy, the direction and strength of relations between forms of past or present TP and efficacy beliefs are less clear. Past and present time frames are less about setting and attaining goals than dwelling on prior experiences or attending to immediate circumstances with little regard for tomorrow's outcomes (Sobol-Kwapinska et al., 2018). Considering different TPs, therefore, should help to understand more comprehensively why some individuals develop strong efficacy beliefs while others do not. 
In addition, self-efficacy can be defined in terms of context or domain (e.g., academic versus social), and the influence of TP may hinge upon the defining features of that domain. Occupational self-efficacy (OSE) refers to the belief that one can mobilize necessary resources needed to meet the situation demands encountered in a work-related occupational domain (Schyns \& von Collani, 2002). OSE, in other words, represents the personal conviction of possessing the ability to solve problems and face the challenges that are part and parcel of a particular occupation, to reach work objectives, and, in general, attain what one sets out to do. An employee with strong OSE beliefs, for example, will feel confident in their ability to reach exacting goals and solve difficult problems along the way. Even if such an employee does not have prior experience in a particular context, or is not particularly skilled at some tasks, a strong OSE would motivate them to persist despite setbacks and live up to expectations until reaching the goal. Notably, not only is OSE worth examining because it influences attitudes such as job satisfaction and organizational commitment (Rigotti et al., 2008; Park \& Jung, 2015), but also because it explains about 16\% additional variance in job satisfaction beyond that explained by general self-efficacy (Schyns \& von Collani, 2002). That said, one objective of this research study is to analyze the relationships between past, present, and future time perspectives and OSE. Examining the relationships between TP and OSE is practice-wise important at the individual and social levels. TP and self-efficacy are key for individuals to develop a strong sense of adequacy, reduce stress, and improve well-being (Bandura, 1995; Zimbardo \& Boyd, 1999). Also, the connection between TP and self-efficacy is related to such socially relevant phenomena as reducing homelessness and improving crisis-coping (Epel et al., 1999).

Individual TP preferences notwithstanding, culture presents a potentially significant contingency for the relationship between TP and OSE. Oettingen (1995) argues that culture affects self-efficacy development by influencing the processes that contribute to it and how success/failure information is weighted and integrated into such judgments. Supporting this point, research suggests that in Japanese culture, individuals take less credit for success than in American culture (Yan \& Gaier, 1994). Accordingly, performance information would convert more easily into self-efficacy beliefs in the U.S. than in Japan. On the whole, culture can well influence the link between TP and OSE by amplifying or diminishing individual propensities to engage in goal setting and striving as well as internal attributions following success/failure outcomes. Examining how culture affects the TP-OSE connections is important to understand why psychological temporarily may affect more intensely self-efficacy development in some societies. The Mexico - United States cultural differences are an appropriate context to examine our propositions. Hofstede's research (Hofstede et al., 2010), as well as the GLOBE findings (House et al., 2004), have affirmed the existence of a Mexico-U.S. cultural distance. More concretely, Cernas-Ortiz and Davis (2016) found that the Mexico-U.S. cultural differences make the relationship between future time perspective and job satisfaction stronger in Mexico than in its northern neighbor. Consequently, this study's second objective is to analyze the moderating role of culture on the relationships between past, present, and future time perspectives and self-efficacy. Examining the moderating role of culture is of utmost importance because the values of different societies may affect relationships between psychological phenomena (Lehman et al., 2004; Santamaría et al., 2018).

In the main, this study contributes to understanding more comprehensively the formation of efficacy beliefs in the work context and it helps to better grasp how the psychological sense of time affects human behavior at work. Remarkably, this study brings culture to the fore as a contingency upon which hinges the relationships between different time perspectives and occupational self-efficacy. 
The rest of this document is as follows: The theoretical framework that backs up a series of hypotheses is presented in the next section. The methodology is presented afterwards. The results and discussion sections follow. This document ends with a conclusion.

\section{Theoretical framework}

Zimbardo and Boyd (1999) posit five TPs which consideration should help to understand comprehensively the TP-OSE connections:

1. Future: Having the future in mind and taking into account the consequences of present-time behavior.

2. Present fatalistic: Focus on the moment with a hopeless or helpless outlook.

3. Present hedonistic: Present focus toward excitement and pleasure.

4. Past negative: A pessimistic outlook of the past resulting from negative events or negative reconstructions of memory.

5. Past positive: Thinking affectively over one's past.

As important as a complete examination of TP influences on OSE may be, measurement limitations preclude it. It has been widely documented the concerns about the structural validity of the Zimbardo Time Perspective Inventory (ZTPI; Perry et al., 2020), being the past positive subscale's reliability particularly low $(\alpha<0.65)$, and an important portion of the present hedonistic subscale`s items prone to cross-load severely on other factors (Worrel \& Mello, 2007; Davis \& Cernas Ortiz, 2017). Per these evidence, no wonder (as mentioned above), researchers usually examine only a subset of such five TPs' implications on other constructs. We, notwithstanding, believe that it is still possible to shed light on the pervasive effects of future, past, and present psychological temporality on OSE by narrowing the examination to those three TP subscales which show adequate psychometric properties, namely: future, present fatalistic, and past negative TP.

Certainly, the above-stated analytical strategy may raise some concerns. However, under the current circumstances of the ZTPI's measurement issues, it is well suited to help us boost our understanding of the TP-OSE connection. By focusing on the negative, and excluding the nostalgic (rosy) view of the past, as well the spontaneous (care-free) outlook of the present, one misses the opportunity to expose the influence that different shades of past and present-time orientations could have on OSE. Nonetheless, it is important to keep in mind the research indicating that the psychological force of negative phenomena and experiences is stronger than that of their positive counterparts (Soroka et al., 2019). Thus, past negative and present fatalistic TP influences on OSE will likely be more potent in comparison to past positive and present hedonistic TP. Also, as future TP and self-efficacy beliefs seem clearly aligned in their motivating potential, it is posited that an examination of the TP-OSE connection focusing on past negative, present fatalistic, and future TP is worthwhile because effect sizes for the proposed relationships are likely to be stronger than the omitted ones. Zimbardo and Boyd (1999) provide evidence in this direction; they report stronger correlations between conscientiousness (a strong self-efficacy correlate) and future $(r=0.57)$, present fatalistic $(r=-0.22)$, and past negative TP $(r=-0.11)$, than those of such personality dimension with past positive $(r=0.04)$ and present hedonistic TP $(r=-0.20)$. 
Having said that, in this document we explain the TP-OSE relationships taking into account that self-efficacy beliefs, in the main, emanate from performance (enactive mastery) experiences (Bandura, 1977, 1995). However, considering also that individuals form efficacy beliefs from experience when they attribute performance to ability (a stable personal resource) and/or effort (a factor under the individual's control; Gist \& Mitchell, 1992), we posit that different forms of TP influence OSE because they both affect the likelihood of experiencing actual enactive mastery and attribution-making following success/failure outcomes.

\subsection{Time perspective and occupational self-efficacy}

At this point, it is worth explaining why different forms of TP may be related to different attributional patterns. Weiner (2010) argues that the interpretation of the past, that is, the perceived causes of prior events (i.e., attributions) determines what is done in the present and what will be done in the future. Epel et al. (1999) suggest that whereas future TP presupposes agency thoughts (i.e., I am in control of what happens in my life) present fatalistic TP does not. Therefore, a strong future TP would foster an interpretation of mastery experiences whereby success is attributed to internal causes (e.g., ability and/or effort), and failure to internal but controllable factors (i.e. effort). Consistent with this argument, Wolf and Savickas (1985) found that whereas an integrated time perspective (akin to future TP) promotes ability and effort attributions for success, it promotes only effort attributions following failure. By comparison, a strong present fatalistic TP would compel individuals to attribute their success (if any) to external reasons (e.g., luck or task easiness) and failure to internal but uncontrollable factors (i.e. ability). Regarding past negative TP, given its intrinsic negativity, any past success would be interpreted as a failure, and such would be attributed to internal uncontrollable factors such as (lack of) ability or external uncontrollable ones such as (bad) luck or other (evil) people. Attributing failure to both internal and external uncontrollable factors is a hallmark of a pessimistic-negative habit of thought (Seligman, 2006).

Based on the previously stated antecedents, future TP will promote OSE development. This TP encompasses the consideration and selection of preferred future states such that individuals place a high value on goals and clearly recognize that present actions have consequences for goal attainment (Zimbardo \& Boyd, 1999; Sobol-Kwapinska et al., 2018). Previous studies indicate that future TP promotes the diligence for building or honing skills needed to reach distant goals with a high-performance standard (Walker \& Tracey, 2012), and does so by emphasizing more proximate goals (Seijts, 1998). Hence, future TP should enhance enactive mastery by promoting goal setting, feedback, and successful goal attainment. Additionally, as future TP fosters attributions that help convert enactive mastery information into self-efficacy beliefs, such TP should be positively related to OSE.

Conversely, a present fatalistic TP may prevent OSE development. This TP describes an orientation of helplessness and hopelessness, as well as convictions that luck plays an equally important role as preparation and hard work in goal attainment (Stolarsky et al., 2014; Sobol-Kwapinska et al., 2018). Given a predominant belief that the future is predestined, present fatalistic TP could undermine attention to and the pursuit of goals. Moreover, even if people set or accept a goal, a disregard for the consequences of present actions might inhibit efforts to build or hone skills needed for achieving goals successfully. Indeed, Abramson et al. (1989) observe that helplessness leads to self-debilitating 
thoughts like "If nothing I do matters, why try?" If present fatalistic TP entails the absence of ambitious goals and hard work, mediocre performance and, thus low levels of enactive mastery are the likely outcomes. In addition, as the TP in mention does not help to convert enactive mastery information into self-efficacy and, which is worse, will likely make individuals to effectively blame failure on their own inadequacy, present fatalistic TP should be negatively related to OSE.

Past negative TP is also likely to block OSE development. Stolarski et al. (2014) portray this TP as emanating from actual unpleasant experiences in one's past, and/or negative reconstructions of it. With past negative TP, individuals are inclined to experience feelings of regret and/or bitterness due to rumination over negative events in the past (Zimbardo \& Boyd, 1999). Eventually, such thoughts and feelings could dampen opportunities for developing enactive mastery by undermining any interest in setting or accepting new goals. That is, dwelling on past events and experiences overshadows any thoughts about future goals and what must be done in the present to reach them (Karniol \& Ross, 1996). Moreover, according to Zimbardo and Boyd (1999) past negative TP relates negatively to impulse control $(r=-.34)$ and energy $(r=-.18)$, thus likely disrupting attention and effort in accomplishing tasks, and, consequently, diminishing performance and stifling enactive mastery. Given that past negative TP may also encourage attributions that could hinder the translation of enactive mastery information into OSE, this TP and OSE should be negatively related.

\section{2. $T$ he moderating influence of culture}

Based on Hofstede et al.'s (2010) findings, the relationship between the TPs under examination and OSE should be stronger in the U.S. than in Mexico. On Hofstede et al.'s (2010) seventy-six-country cultural rankings, compared to Mexico, the U.S. is much higher in individualism (U.S.'s rank = 1 , Mexico's rank $=48$ ), and significantly lower in uncertainty avoidance (U.S.'s rank $=64$, Mexico's rank $=26$ ) and indulgence (U.S.'s rank $=15$, Mexico's rank $=2$ ). The U.S. cultural configuration in tandem with the high level of masculinity ascribed to American culture (the U.S. ranks nineteenth on Hofstede's ranking) helps to explain why the TPs we addressed before should be more strongly related to OSE in that country. Taking masculinity into consideration is important because it promotes achievement motivation (Hofstede et al., 2010), and thus aggressive goal setting and striving, which are directly relevant to OSE development. Notoriously, although on Hofstede's rankings Mexico is more masculine than the U.S. (Mexico ranks eight), Mexico's high uncertainty avoidance would not foster that much achievement motivation. The rest of Hofstede's dimensions (power distance and short versus long-term orientation) could also have implications for TP influences on OSE. However, we believe that focusing on the U.S.-Mexico differences in the aforementioned dimensions could help to understand the phenomenon more parsimoniously. Considering, for example, the short versus longterm orientation dimension could make the study confuse, as it may more likely affect mean levels of future and present TP than amplifying/diminishing their influence on OSE.

As suggested above, there is reason to believe that future TP will be more strongly related to OSE in the U.S. In the first place, Americans would be more inclined to set ambitious goals, as in individualistic societies people are especially motivated by incentives linked to performance (Hofstede et al., 2010), and personal success is very important to self-esteem (Heine \& Hamamura, 2007). Also, as U.S. 
culture is weak in uncertainty avoidance but highly masculine as well, Americans would more likely have a strong need for achievement motivation whereby visible results are important and risk-taking is more likely (e.g., set ambitious goals; Hofstede et al., 2010). If, in addition, cultural indulgence in the U.S. is low, Americans would ascribe a lower valence to leisure activities (e.g., hanging out with friends) than Mexicans (Hofstede et al., 2010), whereby they would more likely strive aggressively to reach their goals. After all, restraining the gratification of human desires is usually associated with high impulse control (Zimbardo \& Boyd, 1999), which is a factor that promotes task success (Wilson, 2014). In addition, because an independent self-construal (i.e., individualism) amplifies the tendency to attribute success to ability (Yan \& Gaier, 1994), U.S. individuals will likely make stronger attributions that foster the conversion of mastery experiences into OSE.

Nonetheless, American culture should also strengthen associations among present fatalistic TP, past negative TP, and OSE. To begin, in the U.S. the undermining effects of present fatalistic and past negative TP on enactive mastery experiences should be intensified given that country's high levels of individualism and masculinity. In highly individualistic and masculine societies, hopelessness, helplessness, and guilt are more profound because they emerge in an "egocentric self" environment where individual agency is clearly understood and valued (Seligman, 2006). Buttressed hopelessness and helplessness make people feel intensely at the mercy of fate (Epel et al., 1999), whereby it makes no sense thinking on structuring the future by means of goals. Moreover, in comparison with Mexico, the U.S.' lower level of indulgence can also intensify present fatalistic TP and past negative TP influences on individuals' low propensities to work diligently towards goal attainment. Low indulgence is associated with diminished happiness (Minkov, 2009), and unhappiness (i.e., depressive thoughts) is associated with fatigue (Leone, 2010). Although, in general, Americans are more prone to self-serving biases (i.e., attributing success to ability rather than to luck or task difficulty) (Yan \& Gaier, 1994), when they take responsibility for failure/defeat, they are more likely to make unhealthy attributions (i.e., internal uncontrollable causes) than people from sociocentric cultures (Seligman, 2006), like Mexico. Thus, in American culture, not only would the TPs in mention incline individuals less to set goals and attain them successfully but also, when a failure occurs, attributions to uncontrollable internal and/or external causes (e.g., ability) would be stronger boosting incompetence rather than efficacy beliefs.

In summary, as explained previously, $\mathrm{TP}$ and OSE should be related because $\mathrm{TP}^{\prime}$ s different facets promote (or hinder) enactive mastery in an occupation and may influence attributions following success (or failure) experiences. However, the strength of the relationship could be amplified by the cultural values of different societies. One such scenario is likely to be observed in the context of the cultural differences between the U.S. and Mexico. The former country's culture might amplify TP effects on OSE more than the latter's given its high levels of individualism and masculinity, and low levels of uncertainty avoidance and indulgence. Formally, we test the following hypotheses:

Hypothesis 1. Future TP is positively related to OSE.

Hypothesis 2. Present fatalistic TP is negatively related to OSE.

Hypothesis 3. Past negative TP is negatively related to OSE.

Hypothesis 4. Future TP is more strongly related to OSE in the U.S. than in Mexico.

Hypothesis 5. Present fatalistic TP is more strongly related to OSE in the U.S. than in Mexico.

Hypothesis 6. Past negative TP is more strongly related to OSE in the U.S. than in Mexico.

Figure 1 shows pictorially our research model. 
Figure 1

TP Relationships with OSE and the Moderation of Culture

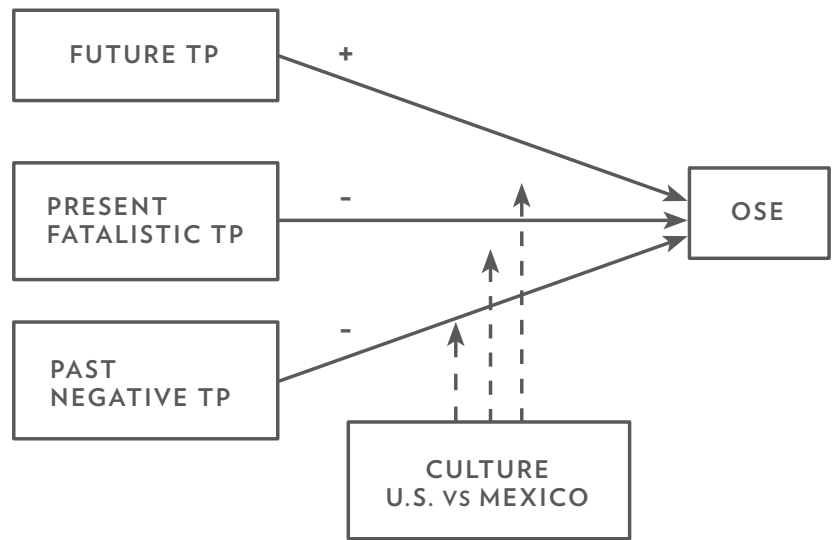

Source: Own elaboration

\section{Methodology}

An empirical analysis was carried out to test the aforementioned hypotheses. The research design was quantitative, non-experimental, cross-sectional, and correlational. We employed existing measurement instruments whose validity and reliability have been documented. In the next paragraphs of this section, we provide all the details relevant to this study's research strategy.

\subsection{Participants and procedure}

This study's sample is non-random. Instead, it consists of individuals to which we had access at the time of the study. Initially, five hundred and eighty-three master level students (MBA) responded to a survey including this study's variables. The final sample size was reduced to 558 observations after discarding incomplete responses (4.3\%). We collected data from a university located in central Mexico $(n=286)$, and another located in the U.S. southwest $(n=272)$. Although differences are statistically non-significant, the Mexican sample contained more women than the U.S. sample (55.2 \% Mex., 48.5 \% U.S.; p > 0.05, Fisher's Exact Test). Most respondents had a full-time job (72 \% Mex., $59.9 \%$ U.S.), but the American dataset included more unemployed individuals than its Mexican counterpart (3.8\% Mex., 14.3 \% U.S.; p < 0.05, Fisher's Exact Test). The Mexicans' average age was 31.3 (SD = 5.77), and the Americans' $29.3(\mathrm{SD}=7.24 ; \mathrm{t}=3.64, \mathrm{p}<0.05)$.

Data were collected by means of a self-administered survey. Students received class extra credit for their participation. Answers to the survey were anonymous to minimize social desirability concerns. Answers to the OSE scale were not "conjectural," but based on actual work experience because all respondents had a current job, or had one in the recent past, that could take into consideration to answer the survey. We asked unemployed students to respond by having in mind their most recent job position. 


\subsection{Instruments}

We measured TP variables employing Zimbardo and Boyd's (1999) $\mathrm{ZTPI}^{2}$ in a Likert-type format ranging from 1 (not at all characteristic of me) to 5 (very characteristic of me). The future TP scale consisted of 13 items, the present fatalistic of 9, and the past negative of 11. "I believe that a person's day should be planned ahead each morning" exemplifies the future TP items. Also, "Often luck pays off better than hard work" and "It is hard for me to forget unpleasant images of my youth" exemplify items on the present fatalistic and past negative scales, respectively.

OSE was measured by means of Schyns and von Collani's (2002) scale (short form), which consists of 8 items capturing individual differences in self-efficacy across a variety of professions and jobs. All items use a Likert-type scale response format ranging from 1 (not at all true) to 7 (completely true). Sample items include "If I am in trouble at work, I can usually think of something to do," and "I meet the goals that I set for myself in my job."

TP and OSE items were translated from English to (Mexican) Spanish prior to the data collection in the above-stated Mexican location. Comparable meaning rather than literal translation was of utmost importance during translation. As a second step, all items were translated back to English by a person unaware of the research's aims. Finally, we analyzed and rectified all possible differences between the back-translated and the original items in the English language. Prior to the data analysis, all survey items were de-cultured by following Bond's (1988) procedure. That is, item responses were standardized within each culture separately to control for differences in scales usage (e.g., acquiescence and leniency) that might alter estimates.

\subsection{Data analysis}

Confirmatory factor analyses (CFAs) were employed to perform a validity assessment. First, for each sample independently, all items were forced to load onto a rough single factor trying to reproduce the observed covariance structure of the data. After, in a second more fine-tuned model, items were assigned to the factors to which they theoretically refer (i.e., future TP, present fatalistic TP, past negative TP, and OSE). The $\chi 2$ difference test was used to compare both models and determine the model that fitted the data best. Provided that the latter model (involving four factors) exhibits adequate fit indices, convergent and discriminant validity assumptions are claimed to be met if the $\chi 2$ difference test suggests the second (fine-tuned) model is superior to the first (rough) one (Hair et al., 2014). In addition, we conducted measurement invariance tests (as described in Byrne, 1998) to rule out validity concerns related to the equivalence of the samples being compared.

In addition, a CFA marker variable analysis involving the comparison of several nested models (see Williams et al., 2010) was employed to examine misleading common-method effects in the data. To do so, we included Cernas-Ortiz and Davis (2016) two-item marker variable in the questionnaire: "I believe that collecting data by means of a survey is important" and "I would like to see a copy of this 
survey's results". These marker variable items should be influenced by different sources of method variance in the same way as this study's main survey items. However, the marker variable items are not theoretically related to TP or OSE. A Likert-type format ranging from 1 (strongly agree) to 7 (strongly disagree) was used to measure the marker variable items. Standard deviations (unstandardized scores) for the marker variable in both samples were above 1.13 indicating that ceiling effects cast little concern about such variable's suitability to reveal method effects.

Means and standard deviations for both Mexico and the U.S. were calculated on unstandardized scores to have a first glance at the data prior to the hypotheses testing. $t$ tests were computed to examine mean differences between the samples. Cronbach's Alpha $(\alpha)$ was employed to analyze the reliability of the measurement scales. Both the t tests and the a were also calculated on unstandardized scores. Bivariate correlations on standardized scores were computed to have a first look at the relationships between the constructs. Effect sizes were analyzed by means of Hedge's g.

Multivariate regression analyses were employed to test the above-stated hypotheses. The respondents' age (standardized within each culture), sex (male, female), and job status (unemployed, employed) were controlled for in all regressions. In addition, a country dummy ( $\mathrm{Mex}=0$, U.S. $=1)$ was included to control for possible differences in OSE between the samples (although such differences were supposed to be eliminated by the scale standardization mentioned previously). To test hypotheses 1, 2, and 3, a regression was performed on the complete sample $(\mathrm{N}=558)$ including control variables and all three TP main terms together. This was done because, as Zimbardo and Boyd (1999) suggested, different $\mathrm{TP}^{\prime}$ s can counteract one another being their interplay what affects behavior and decision making. Thus, analyzing different TPs separately could produce misleading results and conclusions regarding TP effects on other constructs. Another regression was run to test hypotheses 4, 5, and 6. This regression was a traditional moderation analysis and so it included control variables, TP main terms, and interactions obtained by multiplying the country dummy by the TP main terms.

\section{Results}

The results of the data analysis are presented in this section. In the next paragraphs we present the findings concerning the validity assessment, the common method bias test, the descriptive statistics, and the hypotheses testing. By presenting the results we accomplish this study's aims.

\subsection{Validity assessment}

All fit indices for the four-factor solution were in accordance with current standards for acceptable fit (i.e., RMSEA $\leq 0.5$; CFI and NNFI $\geq 0.94$ ). Because the $\chi 2$ difference test suggested that the four-factor solution was superior to the single-factor one (i.e., fitted the data more adequately), convergent and discriminant validity were deemed to be adequate in the data. Concerning measurement invariance, results of these tests indicated that constructs exhibited an acceptable level of configural and metric equivalence for the Mexican and U.S. samples (RMSEA for the metric equivalence model $=0.05, \mathrm{CFI}=0.95)$. 


\subsection{Common method bias test}

This analysis suggested that correlations among the TP dimensions and OSE were robust to same source-same method effects. Average method scores affecting TP and OSE indicators were lower than $0.25 \%$ in both data sets. In turn, this amount is lower than the $20 \%$ suggested by Fuller et al. (2016) as a threshold indicating that method effects do not inflate correlations among the variables significantly.

\subsection{Descriptive statistics}

Table 1 indicates that whereas future, present fatalistic, and past negative TP means are higher in the U.S., OSE average values are higher in Mexico. Except for present fatalistic TP, all differences between the samples are statistically significant. Of course, this is in tune with effect sizes (Hedges' g), which appear to be trivial for present fatalistic TP, small for future TP, and somewhere in between small and medium-sized for past negative TP and occupational self-efficacy. Mean differences, however, should be interpreted cautiously because, as stated above, unstandardized scores might reflect different culturally biased ways of using a numeric scale.

Table 1

Descriptives and Mean Differences

\begin{tabular}{|l|l|l|l|l|l|l|l|l|}
\hline \multirow{2}{*}{ VARIABLES } & \multicolumn{3}{c|}{ MEAN } & \multicolumn{3}{c|}{ STANDARD DEVIATION } \\
\cline { 2 - 10 } & OVERALL & MEX. & U.S. & $t$ & $g$ & OVERALL & MEX. & U.S. \\
\hline 1 Future TP & 3.75 & 3.70 & 3.80 & $-2.34^{* *}$ & 0.20 & 0.51 & 0.50 & 0.52 \\
\hline 2 Present fatalistic TP & 2.25 & 2.21 & 2.29 & -1.42 & 0.13 & 0.63 & 0.66 & 0.59 \\
\hline 3 Past negative TP & 2.57 & 2.40 & 2.74 & $-5.74^{* * *}$ & 0.49 & 0.72 & 0.71 & 0.69 \\
\hline $\begin{array}{l}4 \\
\text { Occupational } \\
\text { self-efficacy }\end{array}$ & 5.77 & 5.94 & 5.60 & $4.44^{* * *}$ & 0.37 & 0.92 & 0.80 & 1.01 \\
\hline
\end{tabular}

${ }^{* *}=p<0.05 ;{ }^{* * *}=p<0.01$

\section{Source: Own elaboration}

Table 2 shows the measurement scales' alpha estimates for the Mexican, U.S., and pooled (overall) samples. As observed, such reliability estimates appear to be adequate. Bivariate correlations (standardized scores) are also presented in the table, indicating (roughly) medium to large effect sizes that are congruent with prior studies. 
Table 2

Reliability and Bivariate Correlations

\begin{tabular}{|c|c|c|c|c|c|c|}
\hline \multirow{2}{*}{ VARIABLES } & \multicolumn{3}{|c|}{$\boldsymbol{\alpha}$} & \multirow[b]{2}{*}{$1 \mathrm{a}$} & \multirow[b]{2}{*}{2} & \multirow[b]{2}{*}{3} \\
\hline & OVERALL & MEX. & U.S. & & & \\
\hline 1 Future TP & 0.75 & 0.70 & 0.79 & & & \\
\hline 2 Present fatalistic TP & 0.76 & 0.76 & 0.76 & $-0.41^{* * *}$ & & \\
\hline 3 Past negative TP & 0.84 & 0.84 & 0.84 & $-0.23^{* * *}$ & $0.57^{* * *}$ & \\
\hline 4 Occupational self-efficacy & 0.91 & 0.90 & 0.92 & $0.34^{* * *}$ & $-0.32^{* * *}$ & $0.30^{* * *}$ \\
\hline
\end{tabular}

Source: Own elaboration

\subsection{Hypotheses testing}

In Table 3, Model 1 includes only control variables. This baseline model explains significant variance in OSE by the small amount of 3.5\%. This model's $\mathrm{R}^{2}$ is used to determine the additional variance explained by models 2 (TP main effects) and 3 (TP-culture interactions).

Hypothesis 1 states that future TP is positively related to OSE. As seen in Table 3 (Model 2), the regression coefficient for the pooled sample indicates that future TP and OSE are positively and significantly related. This supports Hypothesis 1, indicating that as the participants reported higher future TP scores, they also perceived to have a higher OSE.

Hypotheses 2 and 3 assert that present fatalistic TP and past negative TP have a negative association with OSE, respectively. In Table 3 (Model 2) the regression coefficients for the pooled sample support both hypotheses; both, present fatalistic and past negative TP are inversely and significantly related to OSE. In other words, as the participants reported higher present fatalistic and past negative TP, they also had a lower OSE. Adding the TP dimensions under analysis to the baseline model that includes only control variables explains $15.1 \%(\mathrm{p}<0.001)$ additional variance in OSE $\left(\Delta \mathrm{R}^{2}\right)$, which represents an effect a little bigger than medium size.

Table 3

TP Regression Estimates on OSE

\begin{tabular}{|l|l|l|l|}
\hline VARIABLE & MODEL 1 & MODEL 2 & MODEL 3 \\
\hline Constant & -0.109 & 0.094 & 0.131 \\
\hline & $(0.197)$ & $(0.182)$ & $(0.184)$ \\
\hline Age & $0.081 \dagger$ & 0.029 & 0.025 \\
\hline & $(0.042)$ & $(0.039)$ & $(0.039)$ \\
\hline Sex & $-0.172^{*}$ & $-0.214^{* *}$ & $-0.220^{* *}$ \\
\hline & $(0.084)$ & $(0.078)$ & $(0.078)$ \\
\hline Job Status & $0.408^{* *}$ & $0.256^{*}$ & $0.227 \dagger$ \\
\hline
\end{tabular}

(continúa...) 


\begin{tabular}{|c|c|c|c|}
\hline VARIABLE & MODEL 1 & MODEL 2 & MODEL 3 \\
\hline & $(0.133)$ & $(0.124)$ & $(0.125)$ \\
\hline \multirow[t]{2}{*}{ Country dummy } & 0.030 & 0.013 & 0.009 \\
\hline & $(0.084)$ & $(0.078)$ & $(0.078)$ \\
\hline \multirow[t]{2}{*}{ Future TP } & & $0.235^{* * *}$ & $0.218^{* * *}$ \\
\hline & & $(0.041)$ & $(0.06)$ \\
\hline \multirow[t]{2}{*}{ Present fatalist TP } & & $-0.125^{*}$ & -0.098 \\
\hline & & $(0.049)$ & $(0.074)$ \\
\hline \multirow[t]{2}{*}{ Past negative TP } & & $-0.153^{* *}$ & $-0.118 \dagger$ \\
\hline & & $(0.046)$ & $(0.069)$ \\
\hline \multirow[t]{2}{*}{ Future TP x Country dummy } & & & 0.039 \\
\hline & & & $(0.084)$ \\
\hline \multirow[t]{2}{*}{ Present fatalist TP $\times$ Country dummy } & & & -0.063 \\
\hline & & & $(0.099)$ \\
\hline \multirow[t]{2}{*}{ Past negative TP x Country dummy } & & & -0.072 \\
\hline & & & $(0.094)$ \\
\hline$F$ & $4.93^{* *}$ & $17.82^{* * *}$ & $12.79^{* \star \star}$ \\
\hline$R^{2}$ & 0.035 & \begin{tabular}{|l|}
0.185 \\
\end{tabular} & 0.190 \\
\hline$R^{2}$ adjusted & 0.028 & 0.175 & 0.175 \\
\hline$\Delta R^{2}$ & & $0.151^{* * *}$ & 0.005 \\
\hline
\end{tabular}

Numbers within parenthesis are standard errors Source: Own elaboration

As a post-hoc analysis, we conducted a dominance analysis to shed more light on the relative importance of each TP for explaining OSE. We followed Azen and Budescu's (2003) indications to do so. In this scheme, construct $\mathrm{X}$ is said to completely dominate construct $\mathrm{Y}$ in (i.e., to be more important than it for) the explanation of a criterion variable, if in all the possible models in which a predictor needs to be chosen, construct X is always chosen over Y. For this study's data, the dominance analysis indicates that future TP completely dominates present fatalistic and past negative TP, but past negative TP does not completely dominate present fatalistic TP. In short, future TP is a stronger predictor of OSE than the other TPs under analysis. Also, past negative TP is not necessarily a stronger predictor of OSE than its present fatalistic counterpart.

Hypothesis 4, 5, and 6 suggest that future, present fatalistic, and past negative TP have stronger relationships with OSE in the U.S. than in Mexico. As indicated in Table 3, none of the interactions included in Model 3 turned out to be significant. In fact, the interaction coefficients are so small as to be of any major importance. $\Delta \mathrm{R}^{2}$ for Model 3 is tiny indicating that cultural differences between Mexico and the U.S. add very little to the statistical explanation of OSE beyond that explained by TP alone. In sum, hypothesis 4, 5, and 6 are not supported suggesting that effect sizes of the TP-OSE relationships in the U.S. and in its southwestern neighbor differ to a negligible degree.

No multicollinearity issues were detected in any of the above-described regression models (all VIFs were below 10). 


\section{Discussion}

This section is dedicated to put the above-presented research findings into perspective and make explicit their contributions to knowledge and practice. OSE is thought to affect work-related behavior in non-trivial ways, and our findings suggest that TP has potential to shape (or hinder) its development. In this section, this study's limitations and their implications for future research on the topic are addressed too.

\subsection{Preferred time zones and OSE}

Prior arguments suggest that TP (future) and self-efficacy should be related as TP is likely to influence performance outcomes (through goal setting and striving) and thus actual enactive mastery development (Cernas-Ortiz \& Mercado-Salgado, 2020). Advancing such thinking, the present study's arguments indicate that not only should TP be related to OSE by influencing enactive mastery, but also by affecting success attributions to the self. Although the correlational nature of the present study precludes us of from confirming such rationale, the above-presented results support it by indicating that future TP and OSE are positively related. From an attributional perspective, these findings make sense because self-efficacy is unlikely to develop unless individuals think of themselves (actually, their ability and/or effort) as the cause of success (Gits \& Mitchell, 1992). As not all people do this (down to a non-future oriented dominant TP), not everyone forms efficacy thoughts in occupational contexts even though they might, or might not, achieve some work-related goals. Our results on the present fatalistic and past negative TP connections with OSE are relevant at this point. Not only do they indicate that, contrary to future TP, past negative and present fatalistic TP may block OSE development by stifling opportunities to experience enactive mastery, but also, very likely, by influencing attributions that foster incompetency rather than efficacy thoughts in an occupation. Overall, these results add to the understanding of why some individuals have a stronger sense of efficacy than others.

That being said, the findings of the dominance analysis provide further clues to disentangle the relative importance of the TPs under analysis to explain OSE. As hinted above, we cannot make firm causal inferences. However, we can speculate that as future TP turned out to be a stronger predictor of OSE than present fatalistic and past negative TP, efforts to help individuals develop a stronger OSE should focus more on building a future oriented mindset (and its related positive attributions) and less on reducing pessimistic thoughts about the present and/or the past. Furthermore, assuming that personal circumstances, experiences and, hence, learning might determine a person's dominant TP (Zimbardo and Boyd, 1999), instruction, coaching, or therapeutic intervention may help to build or strengthen a person's future TP. We are not able to ascertain whether dampening present fatalistic or past negative TP is more important to raise OSE because our dominance analysis could not establish which one is a stronger OSE predictor. 


\subsection{Cultural effects on TP-OSE relations}

Based on Hofstede et al.'s (2010) findings, different cultural environments may intensify individuals' propensities for setting goals, accepting them, and attributing their successful achievement to the self. In turn, this influence could alter relationships between TP dimensions and OSE. This study's results, however, did not support such view. None the of analyses involving cultural interactions suggested that future, present fatalistic, or past negative TP associations with OSE are significantly stronger in the U.S. than in Mexico. At first sight, it seems that the cultural differences between the countries in mention are not so ample as to make the TP-OSE connections behave differently in one country as compared to the other. After all, so strong and constant is the Mexico-U.S. interplay on such aspects as migration and commerce, that their cultures may be, symmetrically or not, influencing each other. In turn, this would reduce some of their differences and preclude us from detecting significant cultural effects on the TPOSE associations analyzed in this document. An implication of these findings would be that efforts to shape a more OSE contributing TP may work similarly in Mexico and in the U.S.

Nevertheless, a more theoretically relevant, but more extreme interpretation for the lack of support for our cultural arguments is that the TP-OSE connection on its future, present fatalistic, and past negative facets may be cross-culturally invariant. Just as Maslow (1954) proposed needs as universal (i.e., invariant) to understand human motivation, perhaps the potency of TP influences on OSE is such that they vary little among societies (Western culture ones, at least), and so are basically invariant across them. If this were the case, and putting aside some contextual nuances specific to some regions, efforts to help individuals to strengthen a TP more conducive to OSE building and development should work similarly in a variety of cultural settings. Asserting that the TP-OSE relationships are culturally invariant, however, is problematic from the perspective of some propositions (e.g., Oettingen, 1995) indicating that culture can affect not only the sources of self-efficacy across cultures (e.g., the self in individualistic nations and groups in collectivistic ones) but also the way performance information is weighted and integrated into efficacy judgements. One way to resolve the discrepancies between assertions like Oettingen's (1995) and this study's results, is by conceding that the TP-OSE relationships are not culturally invariant, that the Mexico-U.S. cultural differences are strong, but that our specific samples being analyzed are just culturally similar. Maybe, MBA students in Mexico and the U.S. share some similar "educational program culture" that counteracts the influence of national culture. Another possibility is that differences in the TP-OSE relationships, albeit existent, are small enough so as to come out significant only in the statistical analysis of overpowered samples -which is not our case. This possibility, however, takes us back to the question about how big the cultural influences on the TP-OSE relationships could be to warrant a strong substantive (practical) significance or meaning.

\subsection{Practical implications}

Our findings are important for organizational practice and employee well-being. In positive organizational behavior (POB) literature, self-efficacy is regarded as a psychological resource that helps individuals to cope with work-related stress, and an instrument to ameliorate various negative conse- 
quences for persons and organizations (Avey et al., 2010). Thus, evidence suggesting that TP is related to OSE could inform managerial strategies for reducing stress and improving employee well-being and performance across tasks in national and cross-national settings. As previously mentioned, one way to influence TP (future), and thus raise OSE, might be to provide instructions (e.g., cognitive-behavioral training to change attributions), or coaching, that could be implemented as part of the regular training that organizations dispense to their employees and new recruits. However, although in our analysis culture did not significantly affect statistical relationships between TP and OSE, the above-mentioned training might need to be prudently contextualized according to the cultural values of different societies. In Mexico, for example, any coaching aimed at improving future TP, and hence OSE, may have to take into account group-level dynamics. A central element of future TP is the consideration of the consequences that present actions will have on future outcomes. Given that Mexican society is predominantly collectivistic, such training could emphasize the implications that individual present-day behavior and decisions (at work) will have on the future well-being of relevant groups (e.g., family, close friends). Also, in Mexico, it should be taken into account how group feedback might delineate future TP and OSE relevant cognitions. Conversely, the implications of the present-time actions on the individual's future would work best in the U.S.A.

\subsection{Limitations and future research}

In the first place, it is important to mention that we were not able to test hypotheses on the TP-OSE connections including past positive and present hedonistic dimensions. Future research should be devoted to improving the psychometric properties of those ZTPI subscales so that it becomes possible

to explore their effects on OSE and their cultural nuances. Secondly, we assumed enactive mastery as OSE's most influential source, but largely ignored the influence that TP could have on other self-efficacy sources such as vicarious experiences and verbal persuasion. Thus, the possibility remains that other underlying processes may account for our results. Oettingen (1995), for example, argues that whereas self-appraisals of efficacy are likely to center on personal performance attainments in individualistic societies, evaluation by in-group members and social modeling (i.e., vicarious experiences) could be more important in collectivistic ones. Therefore, even if the relationship between a given TP and self-efficacy was invariant across cultures, the mechanisms that connect these constructs may vary with culture. Future research should address these nuances in greater depth. Considering other cultures in addition to the ones examined in this document is also a fruitful avenue for future research testing cultural hypotheses on the TP-OSE connections.

The nature of this study's sample also raises some concerns. Given that respondents were MBA students, the findings may be extended more safely to highly educated individuals relative to the general population of both the U.S. and Mexico. Moreover, as the samples did not include workers who perform manual tasks (e.g. mechanics), the results should be more safely circumscribed to administrative employees or highly specialized technicians. We encourage research that incorporates non-student samples, and people from different regions of the countries we analyzed, to determine if the link between TP and OSE is robust. Actually, per the sample characteristics, in this study is not clear which weighs more: The influence of cultural differences between the United States and Mexico (particularism) or the common 
framework that usually brings together postgraduate university students (universalism). Hence, further, broader investigations are warranted into the interplay of cultural and sub-cultural (e.g. program-specific) influences on work-related attitudes and behavior. Lastly, the self-reported, cross-sectional nature of our data does not lend itself to dig deeper into causality issues, and we recognize that some aspects related to the equivalence between the U.S. and Mexico samples may have altered this study's findings. Although we tried to minimize such issues, it is still possible that they influenced the results.

\section{Conclusion}

Because TP has a powerful and ubiquitous influence on much human behavior and, because self-efficacy is fundamental to every sphere of human endeavor, there are many theoretical and practical implications if the relationships between TP and OSE observed in this investigation are replicated in future studies. The link between TP and OSE, which hinges on the individual's preferred time zone, is particularly relevant to behavior in work organizations. Moreover, the impact of some temporal frames on OSE may well be uniform across cultures, at least those of Mexico and the U.S. Consequently, further research examining TP and various forms of personal efficacy (e.g., task-specific or occupational) in different cultural contexts is important for understanding the effects that psychological temporality has on individual behavior.

\section{References}

Abramson, L., Alloy, L., \& Metalsky, G. (1989). Hopelessness depression: A theory-based subtype of depression. Psychological Review, 96(2), 358-372. https://doi.org/10.1037//0033-295x.96.2.358

Avey, J., Luthans, F., \& Youssef, C. (2010). The additive value of positive psychological capital in predicting work attitudes and behaviors. Journal of Management, 36(2), 430-452. https://doi. org/10.1177/0149206308329961

Azen, R., \& Budescu, D. (2003). The dominance analysis approach for comparing predictors in multiple regression. Psychological Methods, 8(2), 129-148. https://doi.org/10.1037/1082-989X.8.2.129

Bandura, A. (1977). Self-efficacy: Toward a unifying theory of behavioral change. Psychological Review, 34 (2), 191-252. https://doi.org/10.1037//0033-295x.84.2.191

Bandura, A. (1995). Self-efficacy in Changing Societies (1st ed.). Cambridge University Press.

Bond, M. H. (1988). Finding universal dimensions of individual variation in multi-cultural studies of values. Journal of Personality and Social Psychology, 55(6), 1009-1015. https://doi. org/10.1037//0022-3514.55.6.1009

Byrne, B. (1998). Structural Equation Modeling with LISREL, PRELIS, and SIMPLIS: Basic Concepts, Applications, and Programming (1st ed.). Lawrence Erlbaum Associates, Publishers. 
Cernas-Ortiz, D. A., \& Davis, M. A. (2016). Future and past negative time perspective influences on job satisfaction and organizational commitment in Mexico and the United States. Management Research: Journal of the Iberoamerican Academy of Management, 14 (3), 317-338. https://doi. org/10.1108/mrjiam-04-2016-0665

Cernas-Ortiz, D. A. \& Mercado-Salgado, P. (2020). Perspectiva futura de tiempo y autoeficacia: Un análisis de mediación (dureza psicológica, esperanza y vitalidad) en México y EE.UU. Revista Interamericana de Psicología, 54(3), 1-19. https://doi.org/10.30849/ripijp.v54i3.1037

Davis, M., \& Cernas-Ortiz, D.A. (2017). Revisiting the structural and nomological validity of the Zimbardo time perspective inventory. Personality and Individual Differences, 104, 98-103. https:// doi.org/10.1016/j.paid.2016.07.037

Epel, E., Bandura, A., \& Zimbardo, P. (1999). Escaping hopelessness: The influences of self-efficacy and time perspective on coping with homelessness. Journal of Applied Social Psychology, 29 (3), 575-596 https://doi.org/10.1111/j.1559-1816.1999.tb01402.x

Fuller, C., Simmering, M., Atinc, G., Atinc, Y. \& Babin, B. (2016). Common method variance detection in business research. Journal of Business Research, 69 (8), 3192-3198. https://doi.org/10.1016/j. jbusres.2015.12.008

Gits, M., \& Mitchell, T. (1992). Self-efficacy: A theoretical analysis of its determinants and malleability. Academy of Management Journal, 17(2), 183-211. https://doi.org/10.2307/258770

Hair, J., Black, W., Babin, B., \& Anderson, R. (2014). Multivariate Data Analysis (6th ed.). Pearson Education Limited.

Heine, S. J., \& Hamamura, T. (2007). In search of East Asian self-enhancement. Personality and Social Psychology Review, 11(1), 1-24. https://doi.org/10.1177/1088868306294587

Hofstede, G., Hofstede, G, J., \& Minkov, M. (2010). Cultures and Organizations. Software of the Mind (3rd ed.). McGrawHill.

House, R., Hanges, P., Javidan, M., Dorfman, P., \& Gupta, V. (2004). Culture, Leadership and Societies. The GLOBE Study of 62 Societies (1st ed.). SAGE Publications.

Karniol, R., \& Ross, M. (1996). The motivational impact of temporal focus: Thinking about the future and the past. Annual Review of Psychology, 47, 593-620. https://doi.org/10.1146/annurev. psych.47.1.593

Lehman, D., Chui, C. \& Schaller, M. (2004). Psychology and culture. Annual Review of Psychology, 55, 689-714. https://doi.org/10.1146/annurev.psych.55.090902.141927

Leone, S. (2010). A disabling combination: fatigue and depression. The British Journal of Psychiatry, 197(2), 86-87. https://doi.org/10.1192/bjp.bp.109.076604

Maslow, A. H. (1954). Motivation and Personality (1rd ed.). Harper \& Brothers.

Minkow, M. (2009). Predictors of differences in subjective well-being across 97 nations. Cross-Cultural Research, 43(2), 152-179 https://doi.org/10.1177/1069397109332239

Navarro, J., Roe, R. A., \& Artiles, M. I. (2015). Taking time seriously: Changing practices and perspectives in work/organizational psychology. Journal of Work and Organizational Psychology, 31(3), 135-145. https://doi.org/10.1016/j.rpto.2015.07.002

Oettingen, G. (1995). Cross-cultural perspectives on self-efficacy. In Bandura, A. (Ed.), Self-efficacy in Changing Societies (pp. 149-176). Cambridge University Press. 
Park, I., \& Jung, H. (2015). Relationships among future time perspective, career and organizational commitment, occupational self-efficacy and turnover intention. Social Behavior and Personality, 43(9), 1547-1562. https://doi.org/10.2224/sbp.2015.43.9.1547

Perry, J., Temple, E., Worrell, F., Zivkovik, U., Mello, Z., Musil, B., Cole, J., \& Mckay, M. (2020). Different version, similar result? A critical analysis of the multiplicity of shortened versions of the Zimbardo Time Perspective Inventory. SAGE Open, 10 (2), 1-15. https://doi. org/10.1177/2158244020923351

Rigotti, T., Schyns, B., \& Mohr, G. (2008). A short version of the occupational self-efficacy scale: Structural and construct validity across five countries. Journal of Career Assessment, 16(2), 238-255. https://doi.org/10.1177/1069072707305763

Santamaría, A., Cubero, M. \& De la Mata (2018). Towards a cultural psychology: Meaning and social practice as key elements. Universitas Psychologica, 18(1), 1-16. https://doi.org/10.11144/Javeriana.upsy18-1.tcpm

Schyns, B., \& von Collani, G. (2002). A new occupational self-efficacy scale and its relation to personality constructs and organizational variables. European Journal of Work and Organizational Psychology, 11(2), 219-241. https://doi.org/10.1080/13594320244000148

Seijts, G. (1998). The importance of future time perspective in theories of work motivation. The Journal of Psychology, 132(2), 154-168. https://doi.org/10.1080/00223989809599156

Seligman, M. (2006). Learned Optimism. How to Change your Mind and your Life (3rd ed.). Vintage Books.

Shipp, A., Edwards, J., \& Lambert, L. (2009). Conceptualization and measurement of temporal focus: The subjective experience of the past, present, and future. Organizational Behavior and Human Decision Processes, 110(1), 1-22. https://doi.org/10.1016/j.obhdp.2009.05.001

Sobol-Kwapinska, M., Jankowski, T., Przepiorka, A., Oinyshi, I., Sorokowsiki, P. \& Zimbardo, P. (2018). What is the structure of time? A study on time perspective in the United States, Poland, and Nigeria. Frontiers in Psychology, 9, 1-10. https://doi.org/10.3389/fpsyg.2018.02078

Soroka, S. N., Fournier, P., \& Nir, L. (2019). Cross-national evidence of negativity bias in psychophysiological reactions to news. Proceedings of the National Academy of Sciences. 116(38), 1-5. https://doi.org/10.1073/pnas.1908369116

Stolarski, M., Mattews, G., Postek, S., Zimbardo, P., \& Bitner, J. (2014). How we feel is a matter of time: Relationship between time perspective and mood. Journal of Happiness Studies, 15, 809-827. https://doi.org/10.1007/s10902-013-9450-y

Walker, T., \& Tracey, T. (2012). The role of future time perspective in career decision making, Journal of Vocational Behavior, 81, 150-158. https://doi.org/10.1016/j.jvb.2012.06.002

Weiner, B. (2010). The development of an attribution-based theory of motivation: A history of ideas. Educational Psychologist, 45(1), 28-36. https://doi.org/10.1080/00461520903433596

Weiner, B. (2019). Wither attribution theory? Journal of Organizational Behavior, 540(5), 603-604. https://doi.org/10.1002/job.2398

Williams, L., Hartman, N., \& Cavazotte, F. (2010). Method variance and marker variables: A review and comprehensive CFA marker technique. Organizational Research Methods, 13(3), 477-514. https://doi.org/10.1177/1094428110366036 
Wilson, J. (2014). The surprising power of impulse control. Harvard Business Review, 92(5), 24-25.

Wolf, F., \& Savickas, M. (1985). Time perspective and causal attributions for achievement, Journal of Educational Psychology, 77(4), 471-480. https://doi.org/10.1037/0022-0663.77.4.471

Worrell, F. C., \& Mello, Z. R. (2007). The reliability and validity of Zimbardo time perspective scores in academically talented adolescents. Educational and Psychological Measurement, 67(3), 487-504. https://doi.org/10.1177/0013164406296985

Yan. W., \& Gaier, E. (1994). Causal attributions for college success and failure. An Asian American comparison. Journal of Cross-Cultural Psychology, 25(1), 146-158. https://doi. org/10.1177/0022022194251009

Zimbardo, P., \& Boyd, J. (1999). Putting time in perspective: A valid, reliable individual differences metric. Journal of Personality and Social Psychology, 77(6), 1271-1288. https://doi.org/10.1007/9783-319-07368-2_2 